\title{
Knowledge, Attitude and Practice of Resident Doctors for use of Generic Medicines at a Tertiary care Hospital
}

\author{
Kamejaliya Dinesh Zaverbhai, Kapadia Jigar Dilipkumar, Desai Chetna Kalpan, Desai Mira Kiran \\ Department of Pharmacology, B. J. Medical College and Civil hospital, Ahmedabad, Gujarat, INDIA.
}

\begin{abstract}
Objective: To assess knowledge, attitude and practice of resident doctors regarding generic medicines at a tertiary care teaching hospital. Method: This cross sectional study was conducted in 296 resident doctors of a tertiary care teaching hospital using a prevalidated questionnaire, consisting questions of knowledge(17), attitude(8) and practice(10). Data were analyzed for frequency and percentage analysis. Results: A total of $242(81.76 \%)$ resident doctors responded to questionnaire. Respondents were aware of the terms generic medicines(100\%), branded generic $(173,71.4 \%)$ and brand medicines $(216,89.2 \%)$ and regulations regarding prescription of generic medicines in the hospital(178,73.5\%). Majority of participants responded equivocally to: whether generic medicines are cheaper $(154,63.6 \%)$ and equally efficacious $(166,68.5 \%)$ as brand medicines; are easily available $(125,51.6 \%)$ and switching from brand to generic medicines affects the outcome(192,79.3\%). Majority of respondents believed that generic medicines cost less because of inferior quality $(174,71.9 \%)$, have doubtful efficacy in serious diseases(108,44.6\%), can be prescribed in all diseases $(150,61.9 \%)$ and prescription of generic medicines should be compulsory (37\%). Regulations by government (186, 76.8\%), education of medical students $(187,77.2 \%)$ and incentives to doctors $(149,61.5 \%)$ were suggested to improve generic prescribing. All the respondents prescribed generic medicines, consisting of $68.9 \%$ of total prescription medicines. Concerns about efficacy $(242,100 \%)$, safety $(149,61.5 \%)$ and availability $(140,57.8 \%)$ were the major reasons cited for preferring brand medicines. Fifty percent respondents disagreed on substitution of a brand
\end{abstract}

with a generic medicine by pharmacists. Conclusion: Resident doctors have good awareness about generic medicines and prescription regulations and commonly prescribes these medicines. Concerns about efficacy safety and availability of generic medicines are major reasons for preferring brand medicines

Key words: Generic medicines, Knowledge, Attitude, Practice, Resident doctors.

Key message: A good knowledge and prescribing practice regarding generic medicines is observed among resident doctors, however, concerns about efficacy, safety, availability and quality of generic medicines require addressing through educational and regulatory interventions to improve use of generic drugs.

Correspondence :

Chetna Desai

Department of Pharmacology,

B. J. Medical College,

Asarwa, Ahmedabad- 380016, Gujarat, INDIA.

Mobile number: +919712490636

Email: drdesaichetna@gmail.com

DOI: 10.5530/jyp.2017.9.51

\section{INTRODUCTION}

WHO defines generic medicine as "A pharmaceutical product, usually intended to be interchangeable with an innovator product, that is manufactured without a license from the innovator company and marketed after the expiry date of the patent or other exclusive rights". Generic medicines are marketed under the international non-proprietary name of a medicines ${ }^{2}$ after expiry of patent over a brand of a particular company. Since efficacy and safety of these medicines are already established, further research or trial is not required, thus avoiding additional expenditures. ${ }^{3}$ As a result, generic medicines are cheaper than their brand counterparts. However, these are comparable in efficacy and safety as brand medicines, so they provide quality care at an affordable cost. ${ }^{4}$ Generic medicines are important to reduce the healthcare expenditure particularly in developing countries. In India, generic medicines are approved under the guidelines of Central Drug Standard Control Organization (CDSCO), which requires submission of information regarding administrative and prescribing information, product quality, nonclinical as well as clinical study reports. ${ }^{5}$ Indian government started a campaign named 'Jan Aushadhi' in 2008 to provide generic medicines to the population at affordable cost. ${ }^{6}$
A study conducted in Saudi Arabia detected that $79 \%^{7}$ physicians supported the use of generic medicines, while a study in Greece demonstrated that $82.3 \%{ }^{8}$ physicians have positive view on generic medicines, but they still prefer to prescribe original products. Generic medicine prescribing is low in India as shown by certain studies i.e., $27.1 \%{ }^{9}$ in Lucknow and $27.3 \%{ }^{10}$ in Andhra Pradesh. Total expenditure on health care is increasing in India as Per capita total expenditure on health was $\$ 80$ in $2001^{11}$ and $\$ 141$ in $2011 .^{12}$ Promotion of prescription of generic medicines can help to reduce the cost of healthcare.

Resident doctors are independent prolific prescribers in a tertiary care teaching hospital. Data regarding knowledge, attitude and practice of Indian prescribers for the use of generic medicines are lacking. Hence, the present study aimed to evaluate knowledge, attitude and practice (KAP) of resident doctors in a tertiary care teaching hospital regarding generic medicines to identify factors that hinders or encourages prescription of generic medicine.

\section{MATERIALS AND METHODS}

This was a cross-sectional, observational, questionnaire based study conducted at a tertiary care teaching hospital in Gujarat. Prior approval

This is an open access article distributed under the terms of the Creative Commons Attribution-NonCommercial-ShareAlike 4.0 License, which allows others to remix, tweak, and build upon the work non-commercially, as long as the author is credited and the new creations are licensed under the identical terms. 
from the institutional review board (IRB) was taken to conduct the study (IEC/Certi/153/14). The study was conducted in resident doctors over a period of 3 months i.e, from August to October 2014.

A 35 item questionnaire consisting questions of knowledge (17), attitude (8) and practice (10) was prepared and validated for the study (Appendix I). This questionnaire consisted of eight open ended and 27 close ended questions. Open ended questions had space to write opinion while close ended questions had multiple choices to be marked by the respondents. Sixteen questions had a Likert scale ${ }^{13}$ response. Multiple answers were allowed in 5 questions. The questionnaire was pre-tested and validated by five faculty members from clinical departments and a modified questionnaire was prepared accordingly.

The questionnaire was administered to resident doctors of all clinical units after obtaining written informed consent. Resident doctors who did not consent or did not return the questionnaire within stipulated time were excluded from the study. Information collected from the respondents were entered in Microsoft Excel 2007 and analyzed. Responses were analyzed for frequency and percentage analysis.

\section{RESULTS}

Of 296 resident doctors of clinical departments, a total of 242 (81.7\%) doctors responded to the questionnaire. Mean age and average clinical experience of respondents were $26.5 \pm 1.1$ years and 2.6 years respectively.

Evaluation of knowledge: All respondents agreed to knowledge of terms generic medicines, while majority agreed to knowledge of terms brand medicines $(216,89.3 \%)$ and branded generics $(173,71.5 \%)$. A total of $78(32.2 \%)$ respondents stated that they were aware of comparative studies between generic and brand medicines. A total of 178 respondents (73.5\%) mentioned that they were aware of regulations and law enforcement about generic prescriptions in the current setup and were able to provide accurate details in this regard. Thirty eight (25.7\%) respondents mentioned that they were not aware of these regulations, while 26 (10.7\%) respondents did not answer the question.

Evaluation of attitude: Majority of respondents (150, 61.9\%) opined that generic medicines can be prescribed in all diseases, with 92 (38\%) respondents stated that they should be prescribed in chronic diseases. None of the respondents opined that generic medicines should be prescribed in life threatening conditions or not prescribed at all. Various strategies were suggested by respondents to improve generic medicine prescription. (Figure 1).

Evaluation of practice: Respondents mentioned that they treat an average of 175 patients per week writing an average of 129 prescriptions per

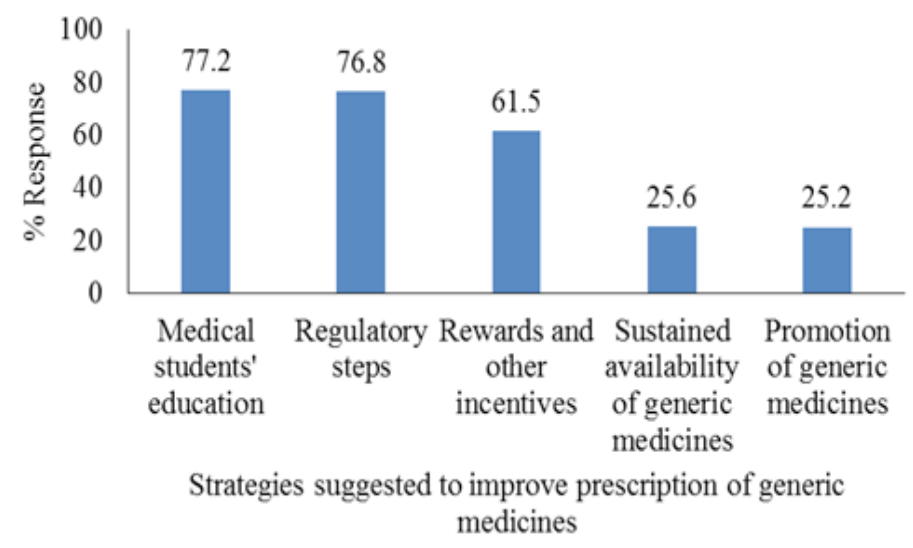

Figure 1: Strategies suggested by resident doctors at a tertiary care hospital to improve prescription of generic medicines $(n=242)$ week. All respondents agreed that they prescribe generic medicines, with these medicines consisting of $68.9 \%$ of their prescription medicines. All the respondents agreed to having sought information regarding generic medicines from sources like internet (240, 99.2\%), books (184, 76\%), peers/colleagues $(157,64.9 \%)$, medical journals $(111,45.9 \%)$, regulatory authorities $(101,41.7 \%)$, medical representatives $(46,19 \%)$ and pharmacists $(2,0.8 \%)$. None of the respondents agreed to having used drug formulary and newsletters. Respondents mentioned that they had never received samples of generic medicines. Respondents opined that they take into consideration cost of medicines (190, 78.5\%), economic status of patient $(186,76.9 \%)$, seriousness of the disease $(159,65.7 \%)$, availability of the medicine $(158,65.3 \%)$ and familiarity with properties of medicine (81, 33.5\%) while prescribing. A total of 109 (45\%) respondents stated that they always consider cost at the time of prescribing while $98(40.5 \%)$ respondents agreed to consider cost most of the time and 35 (14.5\%) respondents agreed to consider cost sometimes at the time of prescription. Majority of respondents stated poor availability $(202,83.5 \%)$ and substitution by pharmacist $(122,50.4 \%)$ as problems faced during prescription of generic medicines. Reasons stated for preference of brand medicines over generic medicines are illustrated in Figure 2.

Responses to a total of 16 questions were assessed on Likert's scale (Table 1).

\section{DISCUSSION}

The present study was conducted to evaluate knowledge, attitude and practice of resident doctors regarding generic medicines at a tertiary care teaching hospital. A 35 item questionnaire was administered to 296 resident doctors, of whom 242 responded. Response rate $(81.7 \%)$ was similar to that reported in 772 physicians $(85.8 \%)$ of primary care, hospital and private settings in Saudi Arabia by Alghasham AA, while evaluating practice and attitude regarding generic medicine prescription. ${ }^{7}$ Most respondents (97\%) in the present study were in their mid or late twenties with relatively less clinical experience ( 2.6 years) since they were still in training phase.

Respondents were aware of the term "generic medicines", however, relatively lesser number knew of terms "brand medicines" (89.3\%) and "branded generics" $(71.5 \%)$. It is important that prescribers understand the difference between these terms, since it may affect selection of drugs while prescribing. Further, only one third of respondents $(32.2 \%)$ were aware of comparative studies between brand and generic medicines. Lack of such information creates doubts regarding quality and efficacy of generic medicines, which reflected in certain responses. Strengthened efforts are required in this direction to improve the level of awareness.

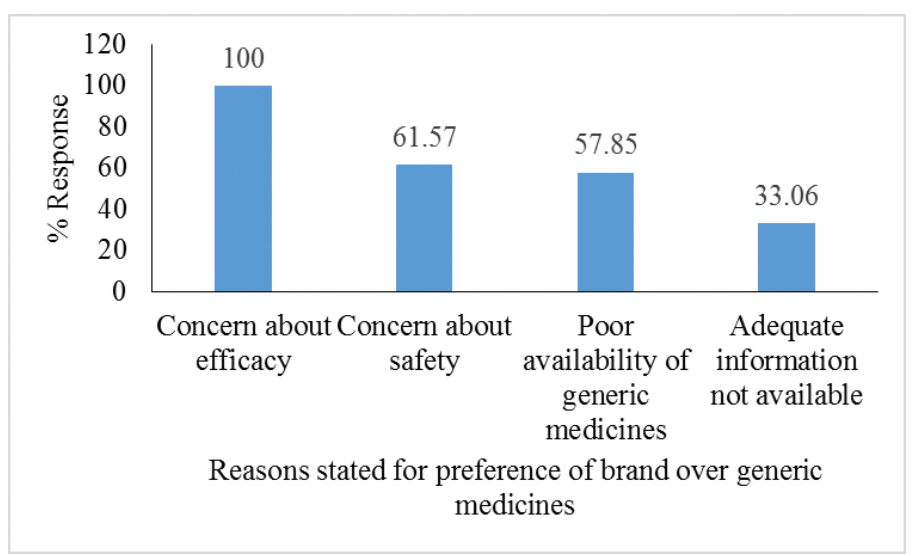

Figure 2: Reasons for preference of brand over generic medicines by resident doctors at a tertiary care hospital $(n=242)$ 
Table 1: Opinions of resident doctors regarding generic medicines at a tertiary care hospital $(\mathbf{n}=\mathbf{2 4 2})$

\begin{tabular}{|c|c|c|c|c|c|c|}
\hline Sr. No. & Question & $\begin{array}{l}\text { Strongly agree } \\
\mathrm{n}(\%)\end{array}$ & $\begin{array}{c}\text { Agree } \\
\mathrm{n}(\%)\end{array}$ & $\begin{array}{c}\text { Neither agree } \\
\text { nor disagree } \\
\mathrm{n}(\%)\end{array}$ & $\begin{array}{l}\text { Disagree } \\
\mathrm{n}(\%)\end{array}$ & $\begin{array}{c}\text { Strongly } \\
\text { disagree } \mathrm{n}(\%)\end{array}$ \\
\hline 1. & $\begin{array}{l}\text { Prescribing of generic medicines should be made compulsory } \\
\text { in a tertiary care hospital }\end{array}$ & $89(36.7)$ & $27(11.2)$ & $82(33.8)$ & $44(18.2)$ & $0(0)$ \\
\hline 2. & $\begin{array}{l}\text { Generic medicines cost less because these are inferior in quality } \\
\text { compared to brand medicines }\end{array}$ & $68(28.1)$ & $\begin{array}{c}174 \\
(71.9)\end{array}$ & $0(0)$ & $0(0)$ & $0(0)$ \\
\hline 3. & $\begin{array}{l}\text { Generic medicines are manufactured in substandard facility } \\
\text { compared to brand medicines }\end{array}$ & $62(25.6)$ & $\begin{array}{c}108 \\
(44.6)\end{array}$ & $72(29.7)$ & $0(0)$ & $0(0)$ \\
\hline 4. & Generic medicines have doubtful efficacy in serious diseases & $27(11.2)$ & $\begin{array}{c}108 \\
(44.6)\end{array}$ & $107(44.2)$ & $0(0)$ & $0(0)$ \\
\hline 5. & $\begin{array}{l}\text { Generic medicines are not easily available in private pharmacy } \\
\text { stores }\end{array}$ & $39(16.1)$ & $\begin{array}{c}103 \\
(42.5)\end{array}$ & $100(41.3)$ & $0(0)$ & $0(0)$ \\
\hline 6. & Generic medicines are cheaper as compared to brand medicines & $0(0)$ & $30(12.4)$ & $154(63.6)$ & $58(23.9)$ & $0(0)$ \\
\hline 7. & Use of generic medicines decrease health expenditure & $3(1.2)$ & $54(22.3)$ & $149(61.5)$ & $36(14.9)$ & $0(0)$ \\
\hline 8. & Generic medicines provide quality care at affordable cost & $30(12.4)$ & $80(33.1)$ & $94(38.8)$ & $38(15.7)$ & $0(0)$ \\
\hline 9. & Generic medicines are as efficacious as their brand counterparts & $0(0)$ & $76(31.4)$ & $166(68.6)$ & $0(0)$ & $0(0)$ \\
\hline 10. & $\begin{array}{l}\text { Generic medicines take similar time to act in the body as brand } \\
\text { medicines }\end{array}$ & $53(21.9)$ & $43(17.8)$ & $146(60.3)$ & $0(0)$ & $0(0)$ \\
\hline 11. & $\begin{array}{l}\text { Switching from brand to generic medicines may affect the } \\
\text { outcome of therapy }\end{array}$ & $30(12.4)$ & $20(8.3)$ & $192(79.3)$ & $0(0)$ & $0(0)$ \\
\hline 12. & $\begin{array}{l}\text { Generic medicines produce similar adverse reactions as brand } \\
\text { medicines }\end{array}$ & $38(15.7)$ & $87(35.9)$ & $117(48.3)$ & $0(0)$ & $0(0)$ \\
\hline 13. & Generic medicines are easily available in the hospital they work & $53(21.9)$ & $20(8.3)$ & $125(51.6)$ & $44(18.1)$ & $0(0)$ \\
\hline 14. & Generic medicines should be promoted like brand medicines & $36(14.8)$ & $56(23.1)$ & $150(61.9)$ & $0(0)$ & $0(0)$ \\
\hline 15. & Awareness for generic medicines is lacking among prescribers & $0(0)$ & $\begin{array}{c}39 \\
(16.11)\end{array}$ & $148(61.1)$ & $55(22.7)$ & $0(0)$ \\
\hline 16. & $\begin{array}{l}\text { Pharmacist can be allowed to substitute the brand with a } \\
\text { generic form }\end{array}$ & $0(0)$ & $55(22.7)$ & $66(27.3)$ & $121(50)$ & $0(0)$ \\
\hline
\end{tabular}

Majority of respondents (73.5\%), however, were aware of hospital regulations regarding prescription of generic medicines, implying adequate sensitization.

While majority respondents (62\%) agreed to prescription of generic medicines in all diseases, which helps reduce cost of treatment, none agreed to use these in life threatening illnesses. This implied a lack of confidence in efficacy of these drugs in serious conditions. Comparative data of brand and generic medicines can help to gain confidence of prescribers in this regard and requires effort on part of manufacturers.

Majority of respondents suggested medical students' education (77.2\%) and regulations regarding generic medicines (76.8\%) to improve prescription of generic medicines. Prescribing patterns are often determined by training received in medical school. Role of generic medicines in providing affordable health care can be emphasized during this period. Regulations regarding prescription of generic medicines are being strengthened in the country at present ${ }^{14}$ and widespread implementation will increase generic medicine prescription. Some of the other recommended strategies i.e. sustained availability, better infrastructure and promotion of generic medicines can also be effectively implemented in the present setup. Financial rewards for general practitioners, medical students' and patient education and information for prescribers ${ }^{15,16}$ were strategies recommended in studies conducted in Australia and Iraq. A systematic review also reported that financial incentives, with educa- tional interventions and audit/feedback have promising value in improving generic medicine prescribing. ${ }^{17}$

A good prescribing practice in terms of percentage of generic medicine prescription $(70 \%)$ was observed in the present study. This can be attributed to regulations regarding prescription of generic medicines in the setup and consideration of cost by majority of respondents (78.5\%) while prescribing. In developing countries, cost of therapy has a major role in deciding treatment and generic medicines help reduce the cost of treatment. A higher number of generic medicines prescription (83\%) was reported in England too. ${ }^{18}$

All resident doctors sought information regarding generic medicines suggesting a good practice. Internet was the most commonly used source since it is easily accessible and provides a wide range of data. The source can be targeted by manufacturers and regulatory authorities for promotion of generic medicines with advertisements or literature to increase awareness. Useful information can also be disseminated through other frequently used sources i.e. books, peers, medical journals and regulatory authorities. Pharmacists and medical representatives were less frequent source of information for respondents in the current study, which can be attributed to lack of promotion of these drugs. Formularies and newsletters were not used by respondents, however, these sources provide valid, reliable information. In contrast, Alghasham AA reported medical representatives as major source of information followed by pharmacists and medical journals, while only $8 \%$ of physicians used internet. ${ }^{7}$ 
Zaverbhai et.al.:Knowledge, attitude and practice of resident doctors regarding generic medicines

Respondents did not receive free samples of generic medicines, indicating a lack of promotion. This can adversely affect prescription of generic drugs since clinicians have less experience with these products. Improved efforts in this regard are required on part of manufacturers.

Respondents preferred brand medicines over generic medicines due to concerns about availability in hospital and private pharmacy, efficacy and safety of generic medicines and lack of adequate information. Addressing these issues can greatly improve use of generic medicines and should be emphasized. A systematic review and critical appraisal had suggested information and education regarding bioequivalence, regulations and quality of generic medicines can improve prescription of these drugs. ${ }^{19}$

Respondents expressed variable opinions regarding regulation of compulsory prescription of generic drugs in a tertiary care teaching hospital. While compulsory prescription can greatly reduce healthcare expenditure, prescribers may have apprehensions regarding quality and efficacy of these drugs and hence, some (18\%) chose not to agree. Majority of respondents (72\%) also had notions that generic medicines are cheaper because these are of inferior quality and manufactured in substandard facility. They also had doubts regarding quality, efficacy, time of onset of action and safety of generic medicines. Lack of information and adequate sensitization leads to such concerns and adversely impacts prescription of these drugs. A study in Turkey ${ }^{20}$ also reported that $82 \%$ of hospital prescribers were unsure about bioequivalence of generic medicines. Majority of respondents reported concerns regarding availability of generic drugs in private pharmacy stores. Ensuring widespread availability or initiatives such as "JanAushadhi" stores can improve the situation and gain confidence of prescribers. Majority of respondents also did not agree to substitution of brand medicine with a generic one by pharmacist. This reciprocates in the fact that respondents preferred brand over generic medicines due to doubts about quality, efficacy and safety of generic medicines and hence, may not desire substitution of former. In contrast, Alghasham AA reported that majority of physicians (79\%) in Saudi Arabia ${ }^{7}$ support generic substitution i.e., dispensing an equivalent generic medicine when a branded medicine is prescribed. ${ }^{21}$

\section{CONCLUSION}

Knowledge of resident doctors about concept and regulations of generic medicines is adequate. Although they prescribe good number of generic medicines, concerns about efficacy, safety and availability are present in this population. Educational and regulatory interventions to address these concerns are required.

\section{ACKNOWLEDGEMENT}

We would like to thank all the resident doctors for participation in the study.

\section{CONFLICT OF INTEREST}

None

\section{REFERENCES}

1. World Health Organization, 2004. Generic drugs. Department of Trade, foreign policy, diplomacy and health of WHO. Geneva: WHO press. Available from: http://www.who.int/trade/glossary/story034/en/. [Last accessed on 10 April, 2014].

2. Bugeja V. Medicines: mere generic facts. J Malta Coll Pharm Pract. 2007;13:42-4.

3. Swain TR, Giri PP. Generic medicines: Old wine in new bottle? J Young Pharm. 2015;7(3):143-4. https://doi.org/10.5530/jyp.2015.3.2.

4. Hassali MA, Alrasheedy AA, McLachlan A et al. The experiences of implementing generic medicine policy in eight countries: A review and recommendations for a successful promotion of generic medicine use. Saudi Pharm J. 2014 22:491-503. https://doi.org/10.1016/j.jsps.2013.12.017 PMid:25561861 PMCid:PMC4281627.

5. Naishi K, Maheshwari D. Documentation requirements for generic drug application to be marketed in India- a review. JPSBR. 2014;4(4):237-42.

6. Department of Pharmaceuticals, Ministry of Chemicals and fertilizers, Government of India. Jan Aushadhi. Generic medicine campaign improving access to medicines. Available from: http://janaushadhi.gov.in/. [last accessed on 1st July, 2016]

7. Alghasham AA. Generic drug prescribing in central Saudi Arabia: Perceptions and attitudes of physicians. Ann Saudi Med. 2009;29(1):24-9. https://doi. org/10.4103/0256-4947.51819 PMid:19139616 PMCid:PMC2813610.

8. Tsiantou V, Zavras D, Kousoulakou H, Geitona M, Kyriopoulos J. Generic medicines: Greek physicians' perceptions and prescribing practices. J Clin Pharm Ther. 2009;34(5):547-54. https://doi.org/10.1111/.1365-2710.2009.01037.x PMid: 19744010

9. Kumari R, Idris MZ, Bhushan V, Khanna A, Agrawal M, Singh SK. Assessment of prescription pattern at the public health facilities of Lucknow district. Indian J Pharmacol. 2008;40:243-7. https://doi.org/10.4103/0253-7613.45148 PMid:21279178 PMCid:PMC3025139.

10. Vijayakumar D, Sathyavati D, Subhashini A. Assessment of Prescribing Trends and Rationality of Drug Prescribing. Int J Pharmacol. 2011;7(1):140-3. https:// doi.org/10.3923/ijp.2011.140.143.

11. The Global Burden of Disease, 2004 update. Department of Health Statistics and Informatics in the information, Evidence and Research Cluster of WHO. Geneva: WHO press, World health report, 1995. Available from: http://www. who.int/whr/2004/annex/country/ind/en/. [Last accessed on 10 April, 2014].

12. India: Health Profile. WHO Global Health Observatory, 2013 update. Department of Health Statistics and Informatics of WHO. Geneva: WHO press, World health report, 1995. Available from: http://www.who.int/countries/ind/en/. [Last accessed on 10 April, 2014].

13. Likert R. A Technique for the Measurement of Attitudes. Archives of Psychology. 1932;140:1-55.

14. Medical Council of India, 2002. Code of ethics regulations 2002. Available from: http://www.mciindia.org/RulesandRegulations2002.aspx. [Last accessed on: 1st November, 2016].

15. Hassali MA, Kong D, Stewart K. Generic medicines: Perceptions of general practitioners in Melbourne, Australia. J Generic Med. 2006;3(3):214-25. https:// doi.org/10.1057/palgrave.jgm.4940122.

16. Sharrad AK, Hassali MA, Shafie AA. Generic medicines: Perception of Physicians in Basrah, Iraq. AMJ. 2009;1(8):58-64.

17. Moe-Byrne T, Chambers D, Harden M, McDaid C. Behaviour change interventions to promote prescribing of generic drugs: a rapid evidence synthesis and systematic review. BMJ Open. 2014;4:e004623. https://doi.org/10.1136/bmjopen-2013-004623 PMid:24833683 PMCid:PMC4024596.

18. Duerden MG, Hughes DA. Generic and therapeutic substitutions in the UK: are they a good thing?. Br J Clin Pharmacol. 2010;70(3):335-41. https://doi. org/10.1111/j.1365-2125.2010.03718.x PMid:20716231 PMCid:PMC2949903.

19. Dunne SS, Dunne CP. What do people really think of generic medicines? A systematic review and critical appraisal of literature on stakeholder perceptions of generic drugs. BMC Med. 2015;13:173. https://doi.org/10.1186/s12916-0150415-3 PMid:26224091 PMCid:PMC4520280.

20. Toklu HZ, Dülger GA, HIdıroglu S, Akici A, Yetim A, Gannemoglu HM, Günes H. Knowledge and attitudes of the pharmacists, prescribers and patients towards generic drug use in Istanbul - Turkey. Pharm Pract (Granada). 2012 Oct-Dec;10(4):199-206. https://doi.org/10.4321/S1886-36552012000400004.

21. Alrasheedy AA, Hassali MA, Aljadhey $\mathrm{H}$ et al. Is there a need for a formulary of clinically interchangeable medicines to guide generic substitution in Saudi Arabia? J Young Pharm. 2013;5:73-5. https://doi.org/10.1016/j.jyp.2013.06.006 PMid:24023460 PMCid:PMC3758099

Article History: Submission Date: 08-09-16; Received Date: 16-10-16; Acceptance Date: 28-12-16.

Cite this article: Zaverbhai KD, Dilipkumar KJ, Kalpan DC, Kiran DM. Knowledge, Attitude and Practice of Resident Doctors for use of Generic Medicines at a Tertiary care Hospital. J Young Pharm. 2017;9(2):263-6. 